\title{
8
}
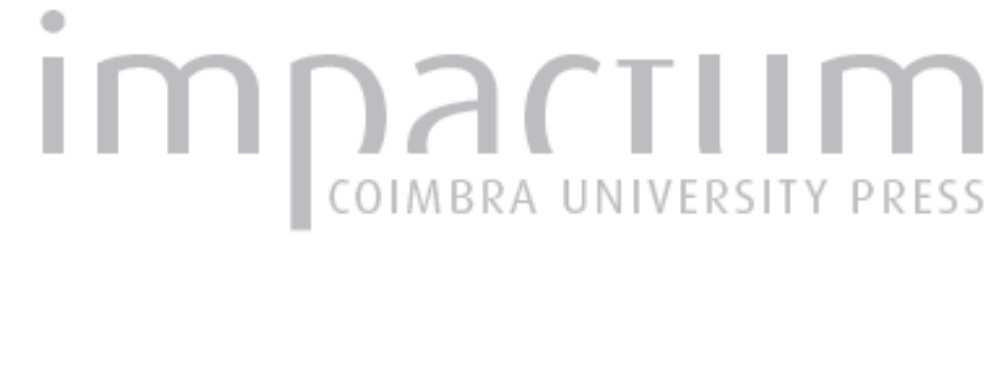

\section{Crise, Precarização e Mudanças Estruturais no Jornalismo: reflexões Sobre \\ Tendências Teóricas}
Autor(es):
Dantas, Juliana Bulhões Alberto; Pinheiro, Elton Bruno Barbosa; Silva, Vinícius Pedreira Barbosa da; Beltrame, Vanessa; David, Hadassa Ester

Publicado por: Imprensa da Universidade de Coimbra

URL

persistente:

URI:http://hdl.handle.net/10316.2/43200

DOI:

DOI:https://doi.org/10.14195/2183-6019_5_3

\section{Accessed : $\quad$ 26-Apr-2023 02:36:08}

A navegação consulta e descarregamento dos títulos inseridos nas Bibliotecas Digitais UC Digitalis, UC Pombalina e UC Impactum, pressupõem a aceitação plena e sem reservas dos Termos e Condições de Uso destas Bibliotecas Digitais, disponíveis em https://digitalis.uc.pt/pt-pt/termos.

Conforme exposto nos referidos Termos e Condições de Uso, o descarregamento de títulos de acesso restrito requer uma licença válida de autorização devendo o utilizador aceder ao(s) documento(s) a partir de um endereço de IP da instituição detentora da supramencionada licença.

Ao utilizador é apenas permitido o descarregamento para uso pessoal, pelo que o emprego do(s) título(s) descarregado(s) para outro fim, designadamente comercial, carece de autorização do respetivo autor ou editor da obra.

Na medida em que todas as obras da UC Digitalis se encontram protegidas pelo Código do Direito de Autor e Direitos Conexos e demais legislação aplicável, toda a cópia, parcial ou total, deste documento, nos casos em que é legalmente admitida, deverá conter ou fazer-se acompanhar por este aviso.

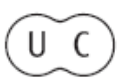


revista de comunicação,

jornalismo e espaço público

\section{5}

Periodicidade

Semestral

Imprensa da Universidade de Coimbra

Coimbra University Press

\section{mediapolis}

crises e os processos comunicativos

crisis and communicative process

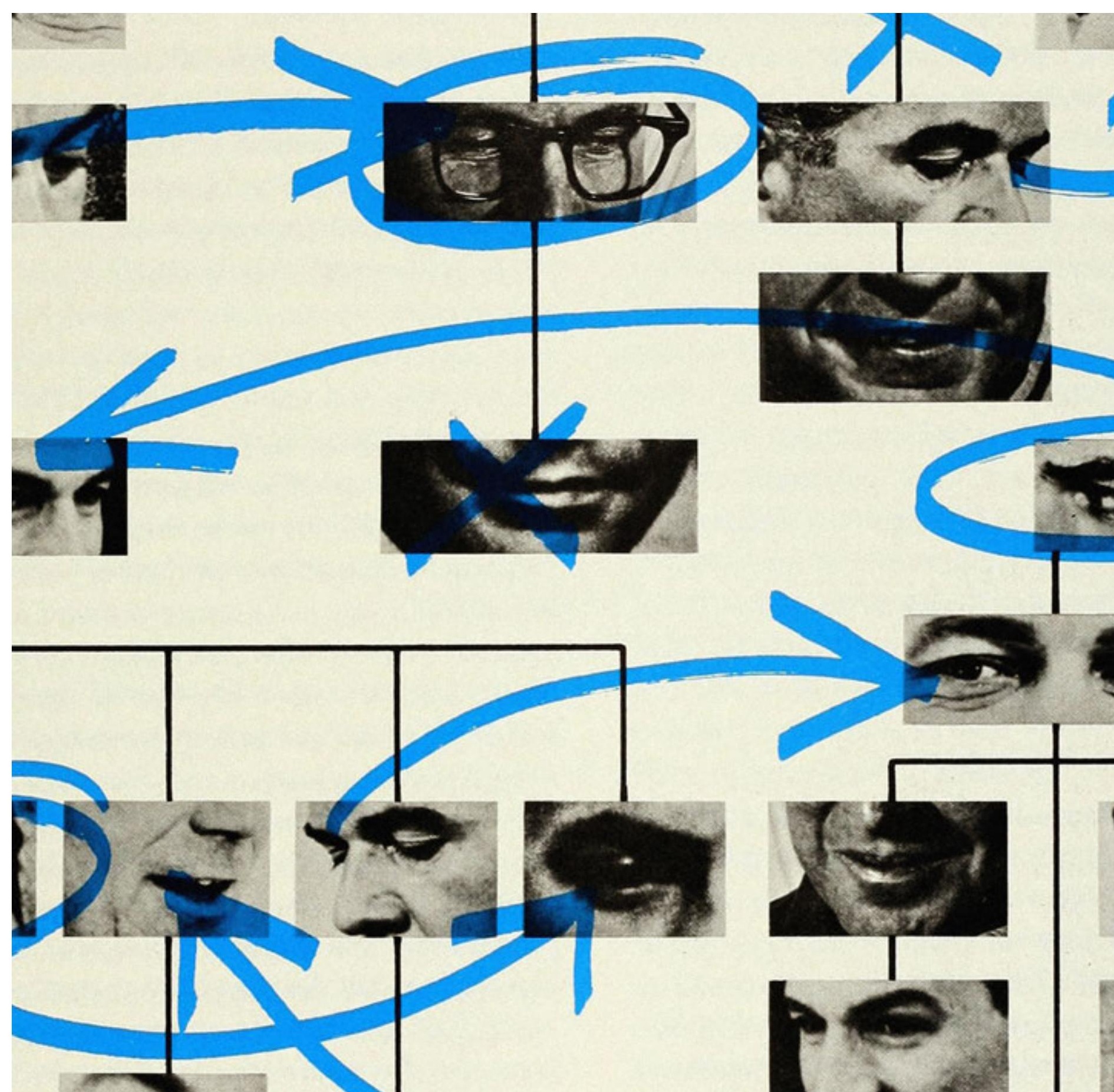




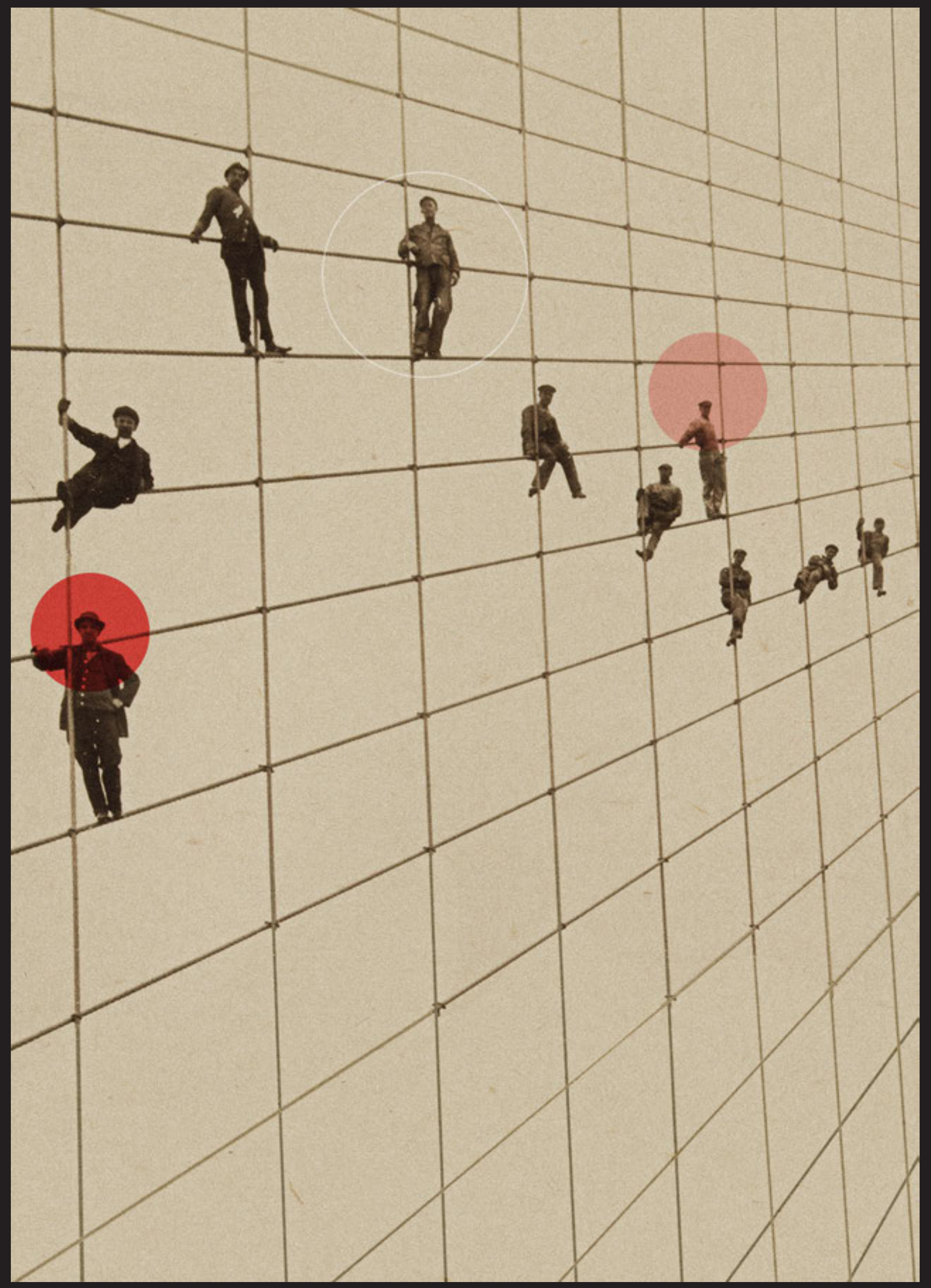




\section{Crise, Precarização e Mudanças Estruturais no Jornalismo:}

\section{Vanessa Beltrame}

Universidade de Brasília

vanessa.beltrame07@gmail.com

Hadassa Ester David

Universidade de Brasília

hadassaester.david@gmail.com

Reflexões Sobre Tendências Teóricas ${ }^{l}$

Crisis, Precarization and Structural Changes in Journalism: Reflections on Theoretical Trends

Resumo

É comum nos depararmos com um discurso de que o Jornalismo atravessa uma crise de valores, de identidade e de mercado. Também é comum a abordagem teórica de que a profissão de jornalista passa por uma precarização e que essa prática social tem sofrido modificações em suas estruturas. Diante desse contexto, traçamos aqui uma discussão teórico-epistemológica acerca do uso dos conceitos-chave crise jornalística, precarização da profissão de jornalista e mudanças estruturais no Jornalismo, tendências teóricas atuais no contexto de pesquisas acadêmicas brasileiras que versam sobre Jornalismo.

Palavras-chave: jornalismo; crise do jornalismo; precarização do jornalismo; mudanças estruturais no jornalismo.
Abstract

Usually we are faced with a speech that Journalism is going through a crisis of values, identity and market. It is also common the theoretical approach that the profession of journalist goes through a precarization and that this social practice has undergone modifications in its structures. In this context, we present here a theoretical-epistemological discussion about the use of the key concepts journalistic crisis, precarization of the journalist profession and structural changes in Journalism, current theoretical trends in the context of Brazilian academic research on journalism.

Keywords: journalism; crisis of journalism; precarization of journalism; structural changes in journalism. 


\section{Introdução}

As tecnologias digitais, ao mesmo tempo que facilitaram a produção e captação de notícias - trazendo mais rapidez e velocidade ao processo -, possibilitaram às empresas concentrarem funções distintas em um único profissional, para que, assim, este venha a realizar mais etapas da produção da matéria jornalística. Tudo isso acompanhado da necessidade de produzir o mesmo conteúdo para diversos modelos, formatos e espaços midiáticos. A informatização permitiu reduzir custos, bem como facilitou a coleta de informações. Sentado, sem precisar de se deslocar, o jornalista recebe rótulos de profissional polivalente e multimídia, embora não receba um salário múltiplo. A exploração aumentou e agora os jornalistas trabalham em mais de uma função e recebem o equivalente a apenas uma. Ou seja, há uma sobrecarga de trabalho, sem remuneração extra. Eles se esgotam mais, bem como estão mais sujeitos ao estresse.

O ofício passa por mudanças e dilemas. Enfrenta crises e desafios. O fato é que a atividade se tem tornado cada vez mais difícil, já que o trabalho e as responsabilidades aumentaram, sem qualquer benefício. O jornalista se sente pressionado a desenvolver novas habilidades e competências para sobreviver. De olho no lucro, a estratégia das empresas de reduzirem os custos vai além das demissões e da transformação do jornalista em um multitarefas. A aceleração da circulação de informação diminuiu o tempo para serem feitas a apuração e a checagem, trazendo empobrecimento e padronização da linguagem, bem como a transformação do conteúdo em simples distração, espetáculo e entretenimento.

Os jornalistas também enfrentam dilemas éticos quanto ao modo de conseguir e divulgar as informações. No meio digital é comum publicar primeiro e revisar, checar ou corrigir depois. O desrespeito pela vida humana fica cada vez mais evidente. Diante de tais condições, o Jornalismo vem se tornando cada vez mais duvidoso; falta credibilidade e as notícias estão cada vez menos confiáveis. Somado a esses fatores, o jornalista agora não detém mais a exclusividade sobre a notícia, no sentido em que, no meio digital, bem como em um contexto de redes sociais digitais, o público não é mais mero consumidor de informação, mas participa também ativamente na construção e circulação das mensagens e conteúdos informativos.

Parafraseando Ciro Marcondes Filho (2002), a saga (dos cães perdidos) continua. O que nos resta, mais do que nunca, é refletirmos sobre valores, identidade e legitimidade da profissão e buscar alternativas para a incerteza desse cenário de convergência digital e crise jornalística.

\section{A (complexa) crise do jornalismo}

As atuais discussões sobre crise do Jornalismo são, na verdade, frutos de velhas inquietudes que compõem a miríade dos dinâmicos debates relacionados ao seu modelo de negócios, aos impactos ocasionados pelas novas tecnologias, às mudanças nas práticas profissionais, à sua relevância enquanto instrumento conformador do espaço público, à pesquisa e à agenda de estudos dessa prática social e de conhecimento (Meditsch, 1997).

Concordamos com Eduardo Meditsch (1997: 11), segundo o qual “ao se deixar de considerar o jornalismo 
apenas como um meio de comunicação para considerá-lo como um meio de conhecimento, estará se dando um passo no sentido de aumentar a exigência sobre os seus conteúdos". Ainda de acordo com o referido autor,

considerar o jornalismo como modo de conhecimento implica também em aumentar a exigência sobre a formação profissional dos jornalistas, que deixam de ser meros comunicadores para se transformarem em produtores e reprodutores de conhecimento (Meditsch, 1997: 12).

Pesquisadores como Florence Le Cam, Fábio Pereira e Denis Ruellan (2015: 13) apontam que "a retórica sobre a crise do jornalismo é por si só um dos discursos mais permanentes e mais recorrentes". Apoiamos essa afirmação, ponderando que tanto a prática jornalística quanto a pesquisa em Jornalismo carregam, ao longo de seus percursos, desafios no que se refere, por exemplo, às mutações dos diversos cenários que os enquadram (social, cultural, tecnológico etc.).

De acordo com Bruno Leal, Phellipy Jácome e Nuno Manna (2013: 01), essa crise:

\section{As reiteradas}

reflexões sobre

\section{tal crise não são}

algo novo para o

Jornalismo. Afinal, "crise" ou "crises"

não surgem

instantaneamente,

mas são frutos

de processos

contextuais,

complexos e

dinâmicos ora é recebida sob olhares positivos, como parte das transformações históricas que envolvem qualquer fenômeno cultural, ora tem como resposta manifestações [...] de apelo à importância de certas características fundamentais do jornalismo.

Para eles, a crença em uma crise do Jornalismo é, nesse sentido, carente de historicidade, o que consequentemente significa uma urgente necessidade de investigar se a "afamada crise seria mesmo do jornalismo, ou se corresponderia, na verdade, aos seus modos de compreensão" (Leal et al., 2013: 1).

Em linhas gerais, a crise do Jornalismo envolve historicamente razões políticas, econômicas, tecnológicas e culturais. As reiteradas reflexões sobre tal crise, as quais parecem atualmente acenar com mais pujança, talvez pelas constantes reconfigurações tecnológicas que ocorrem em um ritmo demasiadamente acelerado, não são algo novo para o Jornalismo. Afinal, "crise" ou "crises" não surgem instantaneamente, mas são frutos de processos contextuais, complexos e dinâmicos. 
Nesse sentido, perguntas como “o Jornalismo está em crise?" e "o Jornalismo vai acabar?" refletem "um sintoma da sensação de insegurança que se abate atualmente sobre a atividade" (Lopes, 2011: 02). A autora Fernanda Lopes (2011) alerta que, antes de perguntar sobre o fim da atividade, o ideal seria questionar sobre os padrões de Jornalismo que estão moribundos, ou, criticamente, dedicar-se a uma abordagem contextual, na qual fiquem explícitos, por exemplo, que práticas e aspectos contemporâneos colaboram para potencializar o que se tem chamado de crise e que precisam ser estudados e reconfigurados.

Da tentativa de explicitar, ainda que sinteticamente, a origem da crise do Jornalismo, cabe-nos, portanto, partir para a reflexão um pouco mais aprofundada a respeito de alguns aspectos aos quais ela está complexamente atrelada na contemporaneidade. Isso porque sabemos que também existem questões inerentes ao atual panorama social e comunicacional que se entrecruzam de modo transversal ao campo jornalístico, cujos produtos, processos e práticas são burilados pela atividade de uma "sociedade em vias de midiatização" (Fausto Neto, 2015: 170).

Para Adriana Barsotti (2014: 13), por exemplo, o Jornalismo é atravessado pela crise da modernidade. Segundo ela, a crise do Jornalismo é anterior à internet, porém esta acelerou o processo. Enfatizando a questão dos jornais, a referida autora destaca a circulação em queda (em detrimento do aumento no número de jornais), o encolhimento da receita publicitária, os cortes nas redações e a expansão rumo aos meios digitais. Barsotti (2014) acredita que a atual fase do Jornalismo, que corresponde ao da era eletrônica, põe em xeque a profissão de jornalista, mas que, no fim das contas, torna-o mais necessário. A pretensão dela não é atribuir as mudanças no campo do Jornalismo exclusivamente ao avanço das novas tecnologias digitais, mas destacar a importância de observarmos essa dinâmica.

Na perspectiva de Lopes (2011: 3), "pensar sobre as instabilidades do jornalismo sob a perspectiva do indivíduo jornalista também é uma estratégia interessante". É preciso ressaltar que, no Brasil, a noção da crise na área foi notadamente aguçada no ano de 2009 , a partir da decisão do Supremo Tribunal Federal em extinguir a exigência do diploma em Jornalismo para a execução da prática profissional. Entretanto, mais do que na exigência diploma, pontuamos uma crise no que se refere à identidade profissional desse sujeito. Lopes (2011: 03-04) explica que "nem sempre os jornalistas foram reconhecidos como profissionais. No Brasil, esse status só começa a ser reivindicado a partir do século XX, embora já se tenha registro da atividade de impressão de periódicos desde 1808".

Consequentemente, também emergem preocupações sobre a pesquisa em Jornalismo. Sobre isso, Fausto Neto (2015: 174) pondera:

\footnotetext{
parece que o jornalismo e os jornalistas estariam na contramão dessas preocupações, na medida em que é repetida a interrogação: qual o futuro dessa profissão? O jornalismo terá futuro após a emergência dessas tecnologias que invadem o tecido social?.
}

Ao relacionar essas inquietações, Fausto Neto (2015) assinala que se tratam de questões abordadas com certa 
ênfase em muitos centros de pesquisa ao se debruçarem sobre a profissão e a formação dos jornalistas no Brasil e no mundo. $\mathrm{O}$ autor enfatiza que as respostas dadas a essas perguntas são, muitas vezes, frutos de locais de fala cujos interesses parecem sem a necessária reflexão analítica, insinuando decretar que a pesquisa e a própria formação em Jornalismo são um problema.

Outras preocupações ponderadas por Fausto Neto (2015), contundentes no que se referem aos atuais reflexos de uma crise em torno do Jornalismo, e que merecem estudos ainda mais especificados são: os temas da agenda jornalística, a ascensão do leitor e a necessidade do jornalista em "recuperar o lugar protagônico de narrador e produtor dos acontecimentos" (Fausto Neto, 2015: 174). São importantes de serem destacadas as mutações ocasionadas pela cultura sociotécnica, na qual os indivíduos passam a ter mais acesso aos processos comunicacionais como sujeitos ativos.

Além disso, não podemos esquecer-nos das complexas reconfigurações nas relações e rotinas de trabalho dos jornalistas, em que cabe a pergunta, também sintomática de crise: o que fazer quando o acontecimento "passa a ser monitorado por um outro desenho de divisão social do trabalho, sobre o qual aparecem muitas variáveis como o da terceirização de atores no âmbito do ofício, a emergência dos administradores de conteúdos" (Fausto Neto, 2015: 177).

Sobre a ascensão do leitor, é importante a compreensão de que se trata não simplesmente de fazer um jornalismo colaborativo, mas que isso reflete o complexo sintoma da crise atual, de "deslocar o leitor para uma atividade produtiva, para a coprodução da conjuntura da noticiabilidade, segundo a lógica do fazer mais com menos..." (Fausto Neto, 2015: 178).

A respeito da necessidade do jornalista em recuperar o lugar protagônico de narrador e produtor dos acontecimentos, talvez esse seja o maior e, de fato, o mais complexo desafio no âmbito da crise do Jornalismo. Contudo, superá-lo depende, sobretudo, do trabalho de pesquisa.

\section{Precarização da profissão de jornalista}

Entendemos por precarização um conjunto de fatores relativos às condições de trabalho, o que faz com que a prática profissional apresente dificuldades no seu pleno exercício. No campo jornalístico, as longas e intensas jornadas de trabalho, o acúmulo de funções e os baixos salários, têm sido citados de maneira recorrente por pesquisadores do assunto como indícios que determinam um processo em andamento de precarização da profissão.

A partir do contexto brasileiro, Graça Druck (2011) mapeou seis tipos de precarização do trabalho: vulnerabilidade das formas de inserção e desigualdades sociais; intensificação do trabalho e terceirização; insegurança e saúde no trabalho; perda das identidades individual e coletiva; fragilização da organização dos trabalhadores; e condenação e descarte do Direito do Trabalho.

Desses, acreditamos que, na profissão de jornalista, prevalece o segundo tipo, que, de acordo com a autora,

é encontrado nos padrões de gestão e organização do trabalho - o que tem levado a condições extremamente precárias, através da intensificação do trabalho (imposição de metas inalcançáveis, extensão da jornada de trabalho, 
polivalência etc.) (Druck, 2011: $48)$.

Samuel Lima (2015) foi mais específico ao apontar cinco indicadores mais fortes de precarização do trabalho do jornalista no Brasil: jornada de trabalho excessiva; intensidade do trabalho; vínculos empregatícios precários; baixos salários; e indícios de multifunção.

Também se tratando da realidade brasileira, ao mostrar as origens desses problemas, Francisco Sant'Anna (2005: 16) relata que os veículos de comunicação "reduziram suas equipes, eliminaram coberturas jornalísticas setorizadas, dispensaram os profissionais". Nesse contexto apresentado pelo autor, é válido lembrar que os jornalistas brasileiros também convivem com o temor constante dos "passaralhos" nas redações. Passaralho é o termo pejorativo que ilustra as demissões em massa nos veículos de comunicação e "remete a pássaros, revoadas de algo que destrói tudo por onde passa" (Fonseca et al., 2013: 1). São também elucidados aspectos de como esses eventos ocorrem e de que maneira eles influenciam no trabalho dos profissionais do campo jornalístico.
Ainda dentro dessa temática, o projeto de Jornalismo de Dados, intitulado Volt Data Lab, realizou o levantamento "Um panorama sobre as demissões de jornalistas brasileiros desde 2012" (Spagnuolo, 2015). $\mathrm{O}$ estudo mostra que, entre 2012 e junho de 2015, pelo menos 1.084 jornalistas foram demitidos, de um total de 3.568 trabalhadores dispensados em aproximadamente 50 empresas de comunicação do Brasil. Entre os que mais demitiram, está a Editora Abril, que, em três anos, mandou embora ao menos 440 pessoas (163 jornalistas), seguida pelos grupos Estado e Folha, com ao menos 65 demissões cada um. Como os dados da pesquisa foram coletados a partir de notícias publicadas em sítios especializados na divulgação de informações sobre a imprensa brasileira, Sérgio Spagnuolo (2015) admite que provavelmente houve bem mais demissões.

Por outro lado, além dos que temem a demissão, há aqueles que mantêm vínculos precários de trabalho. Segundo Lima (2015), esses representam cerca de $30 \%$ dos jornalistas brasileiros, que são os freelancers, os que têm contrato de prestação de serviço, os que trabalham como pessoa jurídica (PJ), entre outros. "Ou seja, praticamente um em cada três profissionais é impactado por esse tipo de vínculo instável e precário" (Lima, 2015: 221).

Em sua pesquisa com jornalistas de Brasília, Cláudio Silva (2014) constata que a prática da "pejotização" - expressão derivada do termo pessoa jurídica, ou seja, que tem registro empresarial - tem aumentado, e que ela é percebida pelos profissionais como uma expressão da precarização. $\mathrm{O}$ autor assinala o fato de que alguns desses trabalhadores afirmam que foram obrigados pelos contratantes a mudar a forma de contrato, abandonando o vínculo celetista para se transformar em PJ.

Entre os prejuízos mais evidentes, estão os materiais: "o trabalhador está sem FGTS, sem $13^{\circ}$ salário, sem participação nos lucros, sem o pagamento de hora-extra, sem plano de saúde, sem seguro-desemprego etc." (Silva, 2014: 113). Ainda sobre os danos ocasionados por essa mudança de vínculo empregatício, o autor identificou diferença nas rotinas produtivas desses profissionais em relação aos colegas celetistas (normalmente trabalham mais, pois não 
recebem horas-extras e nem banco de horas) e até sofrem impacto psicológico.

Marcondes Filho (2009) ressalta que o jornalista teve seu trabalho aumentado com as tecnologias, passou a ter mais atribuições, o contingente nas redações foi reduzido, o prestígio diminuiu, a responsabilidade aumentou e, hoje, qualquer um pode exercer a profissão. Segundo ele, esse conjunto contribui para a precarização profissional, posição que endossamos.

Em relação às questões tecnológicas, suas supostas vantagens vieram acompanhadas de cargas excessivas de trabalho, invasão da vida pessoal e desconfortos físicos como olhos irritados, dores no pescoço e nas costas, lesões por esforços repetitivos. "As organizações [...] substituem cada vez mais o homem pela máquina, implementam novas tecnologias e obrigam o jornalista a adaptar-se freneticamente a elas" (Heloani, 2006: 192).

Zélia Adghirni (2012: 73) admite que "o desenvolvimento das tecnologias digitais acelerou", nas últimas duas décadas, o processo de produção da notícia, que é indissociável da problemática da pressão do tempo.
A convergência de conteúdos em textos, áudio e vídeo rumo a plataformas digitais desconfigura o modo tradicional de produzir e impõe uma carga de trabalho ininterrupta aos jornalistas (Adghirni, 2012: 74).

Embora a autora não use explicitamente a palavra precarização ou precariedade para explicar essa crise profissional, entendemos que ela pode ser interpretada em um contexto de precarização, especialmente no que tange às rotinas produtivas, como citamos anteriormente (Adghirni, 2012).

Ao pesquisar a organização do trabalho jornalístico e de que maneira ela interfere na saúde do profissional, Cristiane Reimberg (2014: 15) concorda que essa precarização traz "consequências negativas para a qualidade do jornalismo praticado e para a saúde física e mental do jornalista". A autora contrapõe o sofrimento decorrente da precariedade das condições de trabalho ao prazer profissional, que aparece em forma de reconhecimento ou de atribuição de um valor positivo à produção jornalística. Ou seja, embora os entrevistados em seu estudo mencionem as longas jornadas, a pressão dos prazos curtos e a baixa remuneração, entre outros, como fatores de sofrimento, eles ainda apontam o prestígio e a vaidade de trabalhar em um veículo reconhecido ou o amor à profissão como fatores de prazer.

Contudo, Reimberg (2014: 15) ressalta que "o prazer oriundo dessa vocação ao Jornalismo pode não ser no futuro uma defesa suficiente para suportar as condições ruins", e aponta que a consequência de um jornalista que não acredita mais no seu trabalho é uma produção alienada e sem identidade, fazendo com que o prazer seja substituído, por fim, pelo sofrimento.

José Ricardo Silveira (2010: 89) traz um recorte histórico-temporal voltado à atualidade, quando diz que "considerando que os jornalistas brasileiros enfrentam um processo de precariedade nas condições de trabalho e de remuneração, [...] eles têm sido hábeis em encontrar saídas que lhes permitam viver com menos privações". Uma dessas saídas é justamente a múltipla jornada de trabalho, que implica em uma carga horária excessiva, com 
longas e intensas horas de labuta a cumprir, influenciando negativamente na saúde dos jornalistas.

\section{Mudanças Estruturais no Jornalismo}

O conceito de mudanças estruturais no jornalismo, atribuído aos canadenses Jean Charron e Jean Bonville (2016), se destaca no âmbito de estudos do Jornalismo no Brasil. O tema é foco de investigação do grupo de pesquisa homônimo vinculado ao Programa de Pós-Graduação em Comunicação da Universidade de Brasília e do conjunto de pesquisadores de países latinoamericanos e francófonos integrantes da Rede de Estudos Sobre o Jornalismo (Réseau d'études sur le journalisme), cujas pesquisas culminaram em quatro edições do Colóquio Mudanças Estruturais no Jornalismo (Mejor), três realizadas no Brasil nos anos de 2011, 2013 e 2015 e uma no Canadá em 2017.

Podemos sintetizar o conceito de mudanças estruturais no Jornalismo como um "conjunto de transformações, que incluem novas formas de produção da notícia, processos de convergência digital e a crise da empresa jornalística enquanto modelo de negócios"
(Adghirni e Pereira, 2011: 39). Nesse contexto, os autores estabelecem três eixos principais de análise sobre a temática: produção da notícia, perfil do jornalista e novas relações com os públicos.

Questionamo-nos: até que ponto as mudanças estruturais são "no" ou "do" Jornalismo? Pensando em mudanças “no" Jornalismo, podemos crer que as mudanças são externas e afetam a profissão; já em mudanças “do" Jornalismo, as mudanças são internas, ou seja, de dentro para fora, oriundas das bases estruturais, ocasionando novas concepções de técnica, prática e linguagem jornalística.

Como Pereira (2015) aponta, há diferenças entre as mudanças de fato e os discursos sobre as mudanças. Ele afirma que, em um primeiro momento, há uma estabilidade no Jornalismo como prática social; em outra perspectiva, há rearranjos nas práticas - sem modificações nas estruturas -, inovações pontuais e segmentações; e, por fim, existem mudanças estruturais, porém raras e oriundas de um processo lento. Em suma, temos que refletir sobre até que ponto a prática jornalística vem se modificando.
Se voltarmos mais no tempo, perceberemos que a linguagem jornalística sempre passou por momentos de ruptura e transformações a cada surgimento de novas formas de produção, de maneira a repensar as técnicas para explorar a expressividade típica de cada veículo midiático. Foi assim com o surgimento dos meios para o desenvolvimento do Radiojornalismo, o Telejornalismo e, atualmente, Webjornalismo. $\mathrm{O}$ primeiro acrescentou o "ao vivo" à voz, a inflexão e o timbre do entrevistado, técnicas de sonoplastia, entre outras singularidades. No segundo caso, a imagem em movimento trouxe maior impressão de realidade, o off, que acrescenta informações enquanto imagens ilustrativas passam ao fundo, dando oportunidade também, à possibilidade de utilização de animações e dramatizações visuais para o melhor entendimento dos acontecimentos por parte do público.

Já no Webjornalismo há o uso de textos, vídeos, sons, imagens em um mesmo ambiente, dentro da sua dinamicidade inerente, trazida pelo hipertexto - fio condutor que proporciona, em vínculos (links), mais informações sobre os assuntos expostos, de modo a dar maior poder de escolha para 
o leitor naquilo que ele pretende se informar, estando relacionado ao caminho de leitura construído junto ao conteúdo jornalístico. Essa singularidade traz novas aberturas para os modelos de negócios, influindo em outro pensar jornalístico e na possibilidade de pensar alternativas em como gerar receitas com as ferramentas recentes.

A criação dos sítios eletrônicos, então, incita uma nova relação com o público e consumo de notícia, representando mudanças no newsmaking. Segundo Thaïs Jorge (2013), as classes de transformações das notícias podem ser identificadas como mutações. Elas podem ser classificadas a partir de dois tipos mais gerais: a mutação verdadeira e a falsa mutação. Esta representa o transporte de conteúdo impresso para a internet, sem nenhuma preocupação com as características de linguagem para o novo suporte. Aquela diz respeito a "quando veículos passaram a ser formatados especialmente para a rede ou mesmo quando sítios baseados na imprensa tradicional criaram produtos específicos para o espaço virtual" (Jorge, 2015: 160).

Dentro do conjunto de transformações, há o fato de que os leitores buscam consumir informações de outras maneiras e estão mais presentes na produção de conteúdos (incentivados, também, por uma maior tentativa de interação). Aliado a essas características, o número de pessoas envolvidas em atividades de autopublicação não para de crescer (Adghirni e Pereira, 2011). Há um deslocamento de leitores dos meios já consagrados para as plataformas digitais, o que não significa uma sentença de morte aos antigos meios ou ao Jornalismo 'tradicional', mas a oportunidade de se repensar as práticas e estratégias dentro dessa nova conjuntura estrutural emergente.

Assim, diante das mudanças tecnológicas, o Jornalismo entrou em uma era de novas rotinas de trabalho, o que trouxe alguns pontos de tensão para a transformação do campo. Segundo Adghirni (2012), no Brasil, eles podem ser divididos em três características: 1) desregulamentação profissional; 2) rotinas produtivas; 3 ) perfil e identidade.

Já vimos algumas consequências sobre as mudanças estruturais na produção da notícia. Já na desregulamentação profissional, houve grande influência da decisão do Supremo Tribunal Federal (STF), em 2010, acerca da inconstitucionalidade da exigência do diploma para exercer a profissão. O impacto da resolução, entretanto, não é de todo conhecido, mas aliando-se aos novos panoramas profissionais, podemos dizer que os "jornalistas brasileiros atravessam uma crise de identidade envolvendo perfis, práticas e relações contratuais de trabalho" (Adghirni, 2012: 68).

Em geral, têm crescido novos tipos de profissionais, tais como jornalistas-multimídias, jornalistas-assessores, jornalistas-precários etc., de modo que esses trabalhadores modificam seu entendimento sobre sua identidade profissional. Para Ruellan (2006), o reconhecimento de uma profissão pela coletividade deve-se à capacidade de definição do seu próprio território e, além disso, os jornalistas estão em um momento de transformação.

\section{Considerações finais}

Não é novidade que a busca e preocupação com o lucro, o Jornalismo como negócio e a notícia como mercadoria sempre foram prioridades para 
os veículos e empresas jornalísticas, dependentes de receita publicitária para sobreviverem economicamente. Neste trabalho, mostramos que as inovações tecnológicas e a inserção da internet nas práticas produtivas jornalísticas acentuaram ainda mais tais necessidades e ocasionaram transformações na área.

As ideias de crise e precarização são reforçadas pelo fato de que se exige cada vez mais do jornalista o desenvolvimento de novas competências, dentro de tempos cada vez mais escassos de produção e acúmulo de trabalho, de maneira a transformar o profissional em pessoa multitarefa, sem necessariamente ele ser mais bem remunerado por suas novas atribuições, dentro do cenário de convergência da produção noticiosa.

Além disso, é evidente que se estabeleceu uma nova relação com o público, bem como mudanças na produção, na rotina; com alterações no produto, na organização, apuração e dos agentes da notícia. Sendo assim, podemos falar e utilizar os termos Mudanças Estruturais no Jornalismo, crise no Jornalismo e precarização da profissão de jornalista como conceitos-chave para reflexão, estudo e pesquisa na área.

Em relação à questão da precarização da profissão e também quanto às mudanças estruturais (ou transformações), é importante inferir que esses conceitos podem ser pontos de partida interessantes a serem aplicados em pesquisas que versam sobre a influência da tecnologia no trabalho do jornalista.

Não queremos apresentar um discurso de que a profissão de jornalista é a mais precária, ou que esta passa por uma precarização mais forte do que outras ocupações. No entanto, não podemos negar que de fato há uma precarização do ofício. Reforçamos que as condições de trabalho estão longe das ideais, o que aponta a necessidade de uma discussão mais aprofundada dos impactos e das consequências disso.

É preciso valorizar e legitimar o jornalista como o mediador, aquele que constrói, do seu lugar de fala, acontecimentos da realidade para a sociedade, claro que, com a colaboração desta, mas não se deixando substituir inteiramente por outros atores sociais ou por instituições que também têm em suas mãos tecnologias para isso. Permanece missão do Jornalismo a mediação social e a propagação de (e dos seus) conhecimentos.

\section{Referências bibliográficas}

Adghirni, Z. (2012). Mudanças estruturais no jornalismo: travessia de uma zona de turbulência. In Pereira, F., Moura, D. e Adghirni, Z. (Orgs.). Jornalismo e Sociedade: Teorias e metodologias. Florianópolis: Insular.

Adghirni, Z. \& Pereira, F. (2011). O jornalismo em tempo de mudanças estruturais. Intexto, 24, 38-57.

Barsotti, A. (2014). Jornalista em Mutação: $O$ cão de guarda ao mobilizador de audiência. Florianópolis: Insular.

Charron, J. \& Bonville, J. (2016). Natureza e Transformação do Jornalismo. Florianópolis: Insular.

Druck, G. (2011). Trabalho, precarização e resistências: novos e velhos desafios? Caderno CRH, 24, 37-57.

Fausto Neto, A. (2015). Jornalismo: do chão da fábrica aos novos processos de redesenho da profissão na sociedade em vias de midiatização. Entrevista. Revista Latino-americana de Jornalismo, 2, 170-187. 
Fonseca, B., Rodrigues, C., Bodenmüller, L. E Viana, N. (10 de junho de 2013). A revoada dos passaralhos. Agência Pública. Retirado de http:// apublica.org/2013/06/revoada-dos-passaralhos/

Jorge, T. (2013). Mutação no Jornalismo: Como a notícia chega à internet. Brasília: Editora da Universidade de Brasília.

Le Cam, F., Pereira, F. \& Ruellan, D. (2015). Introdução: mudanças e permanências do jornalismo. In Moura, D., Pereira, F. \& Adghirni, Z. Mudanças e Permanências do Jornalismo. Florianópolis: Insular. Leal, B., Jácome, P. \& Manna, N. (2013). A "crise" do Jornalismo: o que ela afirma, o que ela esquece. Comunicação apresentada no Encontro Nacional de História da Mídia, UFOP Ouro Preto - Minas Gerais.

Lima, S. (2015). A precarização do trabalho e a saúde dos jornalistas brasileiros. Comunicação apresentada no Colóquio Internacional Mudanças Estruturais no Jornalismo: os silêncios do Jornalismo, Universidade Federal de Santa Catarina, Florianópolis.
Lopes, F. (2011). Jornalismo e suas crises: um olhar sobre as questões da tecnologia, do emprego e do diploma no Brasil. (CIES e-Working Paper N.o 107/2011). Lisboa: CIES-IUL. Marcondes Filho, C. (2002). Comunicação e Jornalismo: A saga dos cães perdidos. São Paulo: Hacker.

Marcondes Filho, C. (2009). Ser Jornalista: $O$ desafio das tecnologias e o fim das ilusões. São Paulo: Paulus.

Medistch, E. (1997). O Jornalismo É uma Forma de Conhecimento? Covilhã: BOCC.

Pereira, F. (21 de março de 2015). Aspectos teóricos e metodológicos da pesquisa em jornalismo. Palestra proferida na Escola de Verão Alaic 2015, Brasília.

Reimberg, C. (2014). Prazer e sofrimento no trabalho do jornalista. Congresso Brasileiro de Ciências da Comunicação, Foz do Iguaçu.

Sant’Anna, F. (2005). Mídia das Fontes: $O$ difusor do jornalismo corporativo. Brasília: Casa das Musas.

Silva, C. (2014). A precarização da atividade jornalística e o avanço da pejotização. Dissertação de mestrado. Brasília: Universidade de Brasília.
Silveira, J. (2010). O jornalista na comunicação das organizações: cultura profissional e autopercepção. Tese de doutorado. Brasília: Universidade de Brasília.

Spagnuolo, S. (12 de junho de 2015). A conta dos passaralhos: um panorama sobre as demissões de jornalistas brasileiros desde 2012. Medium. Retirado de https://medium. com/volt-data-lab/a-conta-dos-passaralhos-953e7e254d4a 